\title{
Prevention of Post-Spinal Anesthesia Shivering: Low Dose Ketamine vs Tramadol
}

\author{
Seyam, Sameh Hamdy MD*
}

*Corresponding Author:

Seyam, Sameh Hamdy

sameh_icu1@yahoo.com

Received for publication January 23, 2020; Accepted May 9 2020; Published online June 6, 2020.

Copyright 2020 The Authors published by Al-Azhar University, Faculty of Medicine, Cairo, Egypt. All rights reserved. This an openaccess article distributed under the legal terms, where it is permissible to download and share the work provided it is properly cited. The work cannot be changed in any way or used commercially.

doi:

10.21608/aimj.2020.22925.1102

"Department of Anesthesia and Intensive care, Faculty of Medicine, Al-Azhar University Cairo, Egypt.

Disclosure: The author has no financial interest to declare in relation to the content of this article. The Article Processing Charge was paid for by the author.

\begin{abstract}
Background: Shivering is described as an involuntary, spontaneous, and repetitive muscular movement. Hypothermia is one of the frequent causes that lower the shivering threshold. Some pharmacologic agents like $N$ methyl d-aspartate receptor antagonists, magnesium sulfate and opioid analgesics have been used for restriction of post-spinal anesthesia shivering.

Aim of the Work: to compare the effectiveness of low-dose intravenous ketamine $(0.2 \mathrm{mg} / \mathrm{kg})$ with that of $(0.5 \mathrm{mg} / \mathrm{kg})$ intravenous tramadol for the inhibition of post-spinal anesthesia shivering in patients who underwent elective surgeries.

Patient and Methods: This is a prospective, randomized, double-blind, placebo-controlled study that was approved by the Mustasharak Hospital Ethical Review Committee, KSA. A total of 150 patients (ASA) I and II aged 21-60 years, who were prepared for surgery under subarachnoid anesthesia from March 2017 to December 2018 were included. After Subarachnoid anesthesia, patients were randomized using the open envelope technique to one of the following three groups: $(\mathrm{K})$ group $=$ ketamine $(0.2 \mathrm{mg} / \mathrm{kg}$ intravenously), $(\mathrm{T})$ group $=$ tramadol $(0.5 \mathrm{mg} / \mathrm{kg})$ and $(\mathrm{S})$ group $=$ saline $(5 \mathrm{~mL}$ normal saline $)$. The tympanic membrane and core temperatures were documented every 5 minutes until the end of the surgery. Shivering scores were reported every 5 minutes and every 10 minutes postoperatively for 60 minutes. Hemodynamic readings were reported every 5 minutes intraoperatively and every 10 minutes postoperatively for 60 minutes. Adverse events were reported. The level of sedation was valued according to a five-point scale.

Results: There was asignificant difference among the groups (tramadol vs placebo and ketamine vs placebo $p \square 0.03$ ). However, there was no significant difference between tramadol and ketamine groups $(p \square 0.261)$. The incidence of grade 3 shivering showed a statistically significant difference ( $p \square 0.03$ ) in the normal saline group as compared to the tramadol group and the ketamine group. The timetaken from theadministration of thestudydrugs to the onset of shivering was statistically different among the groups $(p \sqcap 0.001)$. In all groups, there was a significant decrease in tympanic temperature after subarachnoid anesthesia with respect to baseline values. Tympanic andooretemperaturechanges over time in each group were statistically significant $(p \square 0.002)$.

Conclusion: The prophylactic administration of low-dose IV ketamine $(0.2 \mathrm{mg} / \mathrm{kg})$ or $0.5 \mathrm{mg} / \mathrm{kg} \mathrm{IV} \mathrm{tramadol} \mathrm{is} \mathrm{effective} \mathrm{in} \mathrm{reducing} \mathrm{the} \mathrm{incidence}$ and intensity of shivering in patients having surgery under subarachnoid anesthesia with the priority to tramadol.

Keywords: Ketamine, tramadol, lower abdominal surgery, and shivering
\end{abstract}

\section{INTRODUCTION}

Shivering is described as an involuntary, spontaneous, and repetitive muscular movement. It is one of the frequent problems throughout and following subarachnoid anesthesia due to vasodilation, which could promote fast heat loss and cause a peripheral redistribution of body heat, in the end, hypothermia will be the result that lowers the shivering threshold. ${ }^{1-2}$

Shivering is not a fatal event, even, it may create severe dilemmas in patients with a history of cardiac or pulmonary diseases, such as raised oxygen 
consumption that leads to hypoxemia, lactic acidosis, and increased carbon dioxide production. Furthermore, it increases intraocular and intracerebral pressure, can be annoying for patients, worsens wound pain and impedes ECG monitoring, pulse oximetry, and blood pressure, which may discompose a patient safety issue. ${ }^{3-4}$

Some non-pharmacological methods such as blankets, radiant heat, forced air warmers and increasing the operating theater ambient temperature inhibit shivering through the preservation of the body temperature through reducing heat loss. However, these techniques are costly and tardy to use. ${ }^{5}$ Regarding pharmacologic agents, there are five agents including $\mathrm{N}$-methyl d-aspartate receptor antagonists, opioids, magnesium sulfate, dexmedetomidine, biogenic amines (serotonin 5HT3 receptor antagonist), and cholinomimetics have been used for restriction of post-spinal anesthesia shivering. ${ }^{6}$

Ketamine, a competing receptor antagonist of (NMDA) $N$-methyl D-aspartate has been revealed to prevent postoperative shivering in many articles.

${ }^{7}$ On the other hand, a centrally acting analgesic medicine, Tramadol, with $\mu$-opioid agonist outcomes with least effects at kappa $(\mathrm{k})$ and delta $(\delta)$ receptors, is efficient in the inhibition of post-spinal anesthesia shivering. The mechanism of action is purposed to work within the modulatory influence on central monoaminergic pathways, preventing the neuronal uptake of serotonin and norepinephrine in the spinal cord and increasing hydroxytryptamine secretion, and hence resets the body temperature regulation center. ${ }^{8}$

This is a prospective, randomized, double-blind, placebo-controlled study that was invented to compare the effectiveness of low-dose intravenous ketamine $(0.2 \mathrm{mg} / \mathrm{kg})$ with that of $(0.5 \mathrm{mg} / \mathrm{kg})$ intravenous tramadol for the inhibition of post-spinal anesthesia shivering in patients who underwent elective surgeries. The primary outcome was the prevention of shivering, and the secondary outcome was the effect of study medicines on hemodynamics and level of sedation.

\section{PATIENT AND METHODS}

This is a prospective, randomized, double-blind, placebo-controlled study that was approved by the Mustasharak Hospital Ethical Review Committee, KSA. Written informed consent was received from 150 patients American Society of Anesthesiologist (ASA) I and II aged 21-60 years, who were prepared for surgery under subarachnoid anesthesia from March 2017 to December 2018. Patients with history of diseases involving cardiovascular system or thyroid disease, patients have hypersensitivity to bupivacaine, tramadol, or ketamine, patients have psychogenic disorders, initial temperature $<36{ }^{\circ} \mathrm{C}$ or $>38^{\circ} \mathrm{C}$, history of alcohol abuse, those patients who needed blood transfusion during surgery or who received medications possible to alter thermoregulation, subarachnoid anesthesia with mixture of subarachnoid fentanyl, subarachnoid anesthesia with sedation, such as propofol, or ketamine, or failed subarachnoid anesthesia that turned to general anesthesia were omitted from this study.

Before subarachnoid anesthesia, an 18-gauge intravenous cannula was inserted and $10 \mathrm{~mL} / \mathrm{kg}$ of normal saline was started. Conventional monitoring including electrocardiogram (ECG), heart rate (HR), noninvasive blood pressure (NIBP) and pulse oximetry (SPO2) was fastened. Hemodynamic readings (MAP, $\mathrm{HR}$, and SPO2), tympanic membrane, core, and room temperatures were recorded before subarachnoid anesthesia. Room temperature was fixed at $25^{\circ} \mathrm{C} \pm 1$ for all patients. Preoperatively, no premedication was given to patients. Subarachnoid anesthesia was established at either L3-L4 or L4-L5 in the sitting position by an anesthetist who was blind to the study by using 22 25 gauge Quincke spinal needles (NniEVER CE 0120, made in Nishikata, Koshigaya, Sait Ama, Japan) and $2.8 \mathrm{~mL}(14 \mathrm{mg})$ of heavy bupivacaine $0.5 \%$ was injected (Sunnypivacaine, batch no. 170518, Cairo-Egypt). The subarachnoid anesthesia block was assessed using the Bromage scale and pinprick for the desired motor and sensory block, which was Bromage scale 3 and T6, respectively. Oxygen at $4 \mathrm{~L} /$ minute was conducted via a nasal prong, and patients were covered with drapes but without active warming. Just after subarachnoid anesthesia, patients were randomized using the open envelope technique to one of the following three groups: $(\mathrm{K})$ group $=$ ketamine (ketamine hydrochloride, $50 \mathrm{mg} / \mathrm{ml}$, ROTEXMEDICA GmbH, Germany) $(0.2 \mathrm{mg} / \mathrm{kg}$ intravenously $)$, $(\mathrm{T})$ group = Tramadol (Tramadol Hydrochloride $50 \mathrm{mg} / \mathrm{ml}$, Measham, DE12 7DT, England $)(0.5 \mathrm{mg} / \mathrm{kg}$ intravenously) and (S) group = Normal saline $(5 \mathrm{~mL}$ normal saline). The study medicines were given just after subarachnoid anesthesia administration as coded syringes by the anesthetist who was not included in the patient management. Furthermore, the study medicines and normal saline were prepared in coded $5 \mathrm{~mL}$ syringes and conferred to the responsible anesthetists who were blinded to study group allocations and were given as an intravenous bolus.

Tympanic membrane temperature ( Weich Allyn Braun Thermoscan ${ }^{\circledR}$ PRO 6000) and core temperatures (Nasopharyngeal thermometer) were observed and documented every 5 minutes until the end of the surgery. Shivering scores were reported every 5 minutes and every 10 minutes 
postoperatively for 60 minutes. Shivering was ranked using a scale similar to that validated by Tsai and $\mathrm{Chu}^{9}$ (Table 1).

A rescue drug was given intravenously in the form of Pethidine $(25 \mathrm{mg})$ for patients who developed grade 3 or grade 4 shivering within 15 minutes of subarachnoid anesthesia despite giving a prophylactic dose of one of the study medicines.

\begin{tabular}{|c|l|}
\hline $\begin{array}{l}\text { Grade of } \\
\text { shivering }\end{array}$ & Clinical sign \\
\hline 0 & No shivering \\
\hline 1 & $\begin{array}{l}\text { Peripheral vasoconstriction or } \\
\text { piloerection, but no obvious shivering }\end{array}$ \\
\hline 2 & $\begin{array}{l}\text { Muscular activityin only one muscle } \\
\text { group }\end{array}$ \\
\hline 3 & $\begin{array}{l}\text { Muscular activityin more than one } \\
\text { muscle group, but not generalized }\end{array}$ \\
\hline 4 & Shivering involving the whole body \\
\hline
\end{tabular}

Table 1: grades of shivering

Hemodynamic readings in the form of HR, MAP, and SPO2 were reported every 5 minutes intraoperatively and every 10 minutes postoperatively for 60 minutes. Adverse events in the form of nausea and vomiting, hypotension, hallucinations and sedation were reported. If the patient's heart rate declined below 50 bpm, atropine $0.5 \mathrm{mg}$ was given intravenously. Also, hypotension was managed with $5 \mathrm{mg}$ of ephedrine intravenously and crystalloids. If the patient exhibited grade 1and more nausea and vomiting, 10 mg of metoclopramide administered intravenously. The level of sedation was assessed according to a five-point range were [1] alert and oriented, [2] somnolent, [3] closed eyes, arousable on a verbal order, [4] closed eyes, arousable to physical stimuli and [5] closed eyes and patient unarousable to physical stimuli.

Sample size calculationand statistical analysis The sample size estimated utilizing the conclusions of a former thesis, where the percentage of shivering following the cesarean section under SA after taking tramadol $0.5 \mathrm{mg} / \mathrm{kg}$ was $16 \%(\mathrm{P}=0.16) .{ }^{15}$ The sample size calculated using $0.05 \%$ as an alpha value and $90 \%$ as a power. Data were analyzed using SPSS version 20 statistical package software. Chi-square test was used to interpret the difference between ASA physical status, the number of patients developing shivering, the presence of nausea and vomiting, and hallucinations. Results are displayed as medians (interquartile range), and definite numbers of proportions are displayed as percentages. A $p$-value $=0.05$ was considered as statistically significant.

\section{RESULTS}

A total of 150 patients who underwent surgeries under subarachnoid anesthesia were enrolled in this study. Of these patients, 50 were allocated to the ketamine group (Group K), 50 to the Tramadol group (Group T) and 50 to the Nomal saline group/placebo group (Group $\mathrm{S}$ ).

Regarding demographic characteristics (age, weight, and height), ASA physical status, and duration of surgery, they were comparable and there were no significant differences among the groups (Table 2).

\begin{tabular}{|l|c|c|c|c|}
\hline \multicolumn{1}{|c|}{ Characteristics } & GroupT $(\mathbf{n = 5 0})$ & GroupK $(\mathbf{n}=\mathbf{5 0})$ & GroupS $(\mathbf{n}=\mathbf{5 0})$ & $\boldsymbol{p}$-value \\
\hline Age $($ years) & $25 \pm 5$ & $28 \pm 7$ & $28 \pm 7$ & 0.0613 \\
\hline Weight $(\mathrm{kg})$ & $69 \pm 8$ & $70 \pm 13$ & $70 \pm 13$ & 0.1631 \\
\hline Height $(\mathrm{cm})$ & $166 \pm 12$ & $165 \pm 13$ & $165 \pm 13$ & 0.095 \\
\hline AS A & & & & 0.923 \\
\hline I $(\%)$ & $25(50 \%)$ & $26(52 \%)$ & $26(52 \%)$ & \\
\hline II $(\%)$ & $25(50 \%)$ & $24(48 \%)$ & $24(48 \%)$ & 0.090 \\
\hline $\begin{array}{l}\text { Duration of surgery } \\
\text { (minutes) }\end{array}$ & $58 \pm 15$ & $51 \pm 16$ & $51 \pm 16$ & \\
\hline
\end{tabular}

Table 2: Demographic and surgical characteristics. Notes: Data are presented as mean \pm SD or numbers (proportions). Regarding recorded baseline hemodynamic data (mean arterial pressure), pulse rate and $\mathrm{SPO}_{2}$, there was no significant difference among all groups as shown in (Table 3). Preoperative tympanic temperatures were also comparable among the groups, and room temperatures were fixed for all patients(Table 3).

\begin{tabular}{|l|c|c|c|c|}
\hline Parameter & Group T $(\mathbf{n = 5 0})$ & Group K $(\mathbf{n = 5 0})$ & Group S $(\mathbf{n}=\mathbf{5 0})$ & $\boldsymbol{p}$-value \\
\hline MAP $(\mathrm{mmHg})$ & $87 \pm 11$ & $90 \pm 10$ & $88 \pm 14$ & 0.431 \\
\hline Pulse rate $(\mathrm{bpm})$ & $91 \pm 20$ & $91 \pm 21$ & $95 \pm 22$ & 0.541 \\
\hline $\mathrm{SPO}_{2}(\%)$ & $98.2 \pm 1$ & $98,1 \pm 1$ & $97.9 \pm 1$ & 0.313 \\
\hline $\begin{array}{l}\text { Tympanic } \\
\text { temperature }\left({ }^{0} \mathrm{C}\right)\end{array}$ & $36.6 \pm 0.44$ & $36.5 \pm 0.42$ & $36.7 \pm 0.5$ & 0.095 \\
\hline
\end{tabular}

Table 3: Preoperative baseline data. Notes: Data are presented as mean \pm SD. 
Seyam et al, post spinal Anes. Shivering: Low Dose Ketamine vs Tramadol

Regarding intraoperative fluids administered and total blood loss there was no significant difference among all groups as shown in (table 4).

\begin{tabular}{|l|c|c|c|c|}
\hline Characteristics & Group T $(\mathbf{n}=\mathbf{5 0})$ & Group K $(\mathbf{n}=\mathbf{5 0})$ & Group S $(\mathbf{n}=\mathbf{5 0})$ & $\boldsymbol{p}$-value \\
\hline $\begin{array}{l}\text { Total intravenous fluid } \\
(\mathrm{mL})\end{array}$ & $2,000 \pm 700$ & $1,800 \pm 500$ & $2,100 \pm 100$ & 0.137 \\
\hline Estimated blood loss $(\mathrm{mL})$ & $400 \pm 150$ & $350 \pm 200$ & $400 \pm 150$ & 0.233 \\
\hline
\end{tabular}

Table 4 :Intraoperative clinical characteristics Notes: Data are presented as mean \pm SD.

Regarding the incidence of shivering, shivering was seen in 28 patients $(56 \%)$ in the tramadol group, 18 patients (36\%) in the ketamine group and 35 patients $(70 \%)$ in the normal saline group, and the overall incidence of shivering was $81 / 150$ (54\%; $p \square 0.03$ ). Post hoc test showed that there was a significant difference among the groups (tramadol vs placebo and ketamine vs placebo $p \square 0.03)$. However, there was no significant difference between tramadol and ketamine groups ( $p \square 0.261)$ as shown in (table 5).

\begin{tabular}{|l|c|c|c|c|c|}
\hline & Parameter & $\begin{array}{c}\text { Group T } \\
(\mathbf{n = 5 0})\end{array}$ & $\begin{array}{c}\text { Group K } \\
(\mathbf{n = 5 0})\end{array}$ & $\begin{array}{c}\text { Group S } \\
(\mathbf{n = 5 0})\end{array}$ & $p$-value \\
\hline Shivering (\%) & No & $22(44 \%)$ & $32(64 \%)$ & $15(30 \%)$ & $0.003^{*}$ \\
\hline & Yes & $28(56 \%)$ & $18(36 \%)$ & $35(70 \%)$ & \\
\hline $\begin{array}{l}\text { Severity of } \\
\text { Shivering (\%) }\end{array}$ & Grade 2 & 17 & 11 & 10 & $0.031^{*}$ \\
\hline & Grade 3 & 11 & 7 & 22 & \\
\hline $\begin{array}{l}\text { Time to } \\
\text { shivering } \\
\text { (minutes) }\end{array}$ & Grade 4 & $31.5 \pm 11$ & $29.5 \pm 9$ & $14 \pm 6$ & $<0.001^{* *}$ \\
\hline & & & & & \\
\hline
\end{tabular}

Table 5: Incidence and percentage of shivering severity. Notes: Data are presented as mean \pm SD, numbers (percentage).

*Chi-square test, ${ }^{* *}$ ANOVA test. $p \leftrightharpoons 0.05$ is significant.

Grade 2 shivering was recorded in $17(34 \%)$ patients in the tramadol group and $11(22 \%)$ patients in the ketamine group, whereas it was recorded in $10(20 \%)$ patients in the normal saline group. The incidence of grade 3 shivering showed a statistically significant difference $(p \square 0.03)$ in the normal saline group (22 [44\%]) as compared to the tramadol group (11 [22\%]) and the ketamine group (7 [14\%]).

The time taken from theadministration of the studydrugs to the onset of shivering was statistically different among the groups $(p \square 0.001)$. Patients in the saline group had anearlier onset of shivering, as compared to patients in the tramadol ( $p \square 0.001)$ and ketamine ( $p \square 0.013$ ) groups (Table 5)

In all groups, there was a significant decrease in bothtympanic and core temperatures after subarachnoid anesthesia with respect to baseline values. Tympanic and core temperature changes over time in each group were statistically significant ( $p \square 0.002$ ); however, there were no significant differences among groups (Figure 1) and (Figure 2). 


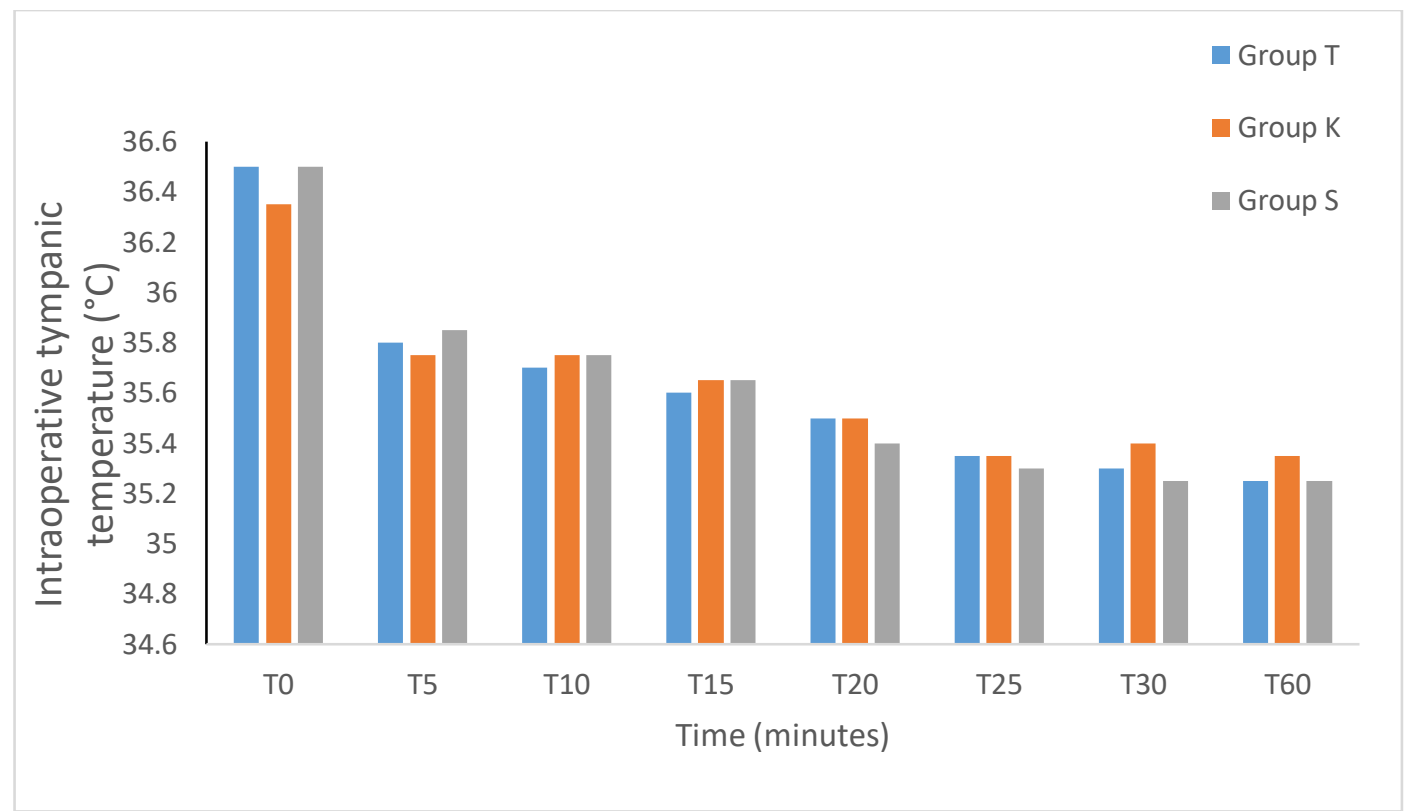

Figure (1) Changes in tympanic temperature with time in the intraoperative period among the groups

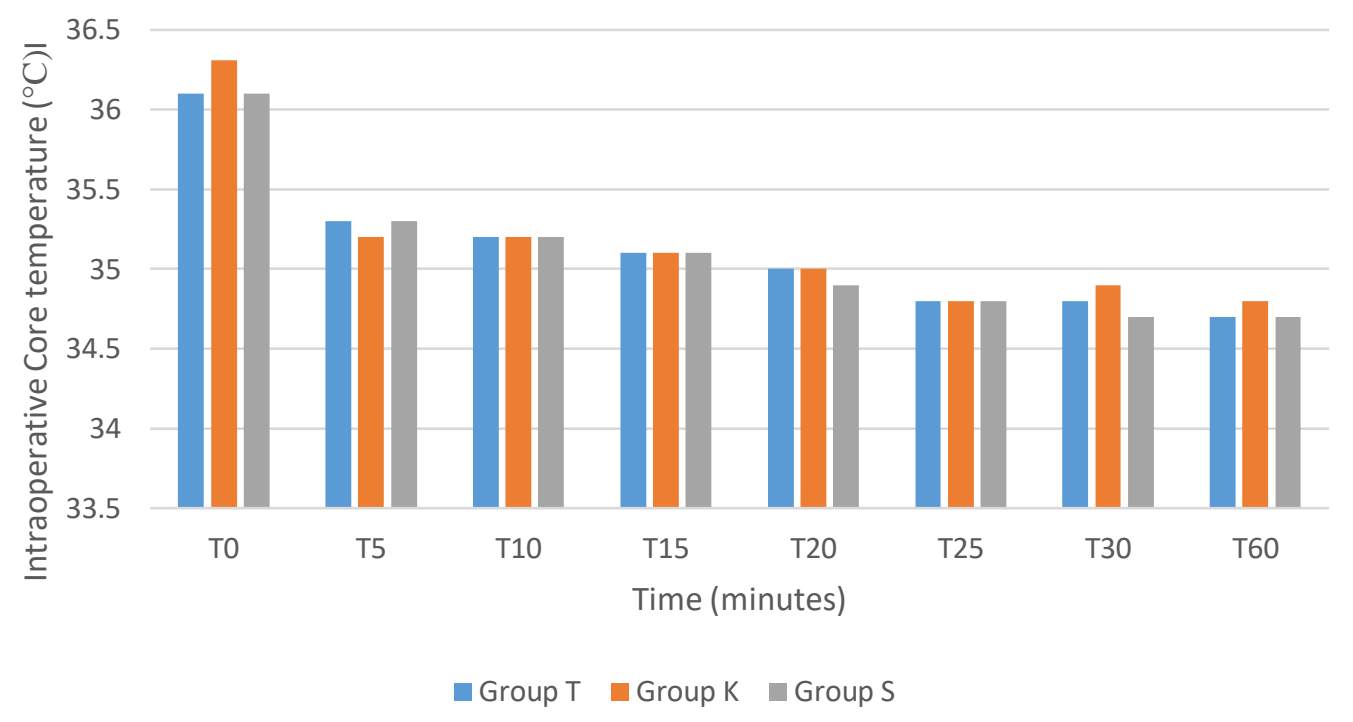

Figure (2) Changes in core temperature with time in the intraoperative period among the groups. In the recoveryroom, thetympanic temperature was recorded every 10 minutes for 1 hour. The mean tympanic temperature increased in all groups with respect to $\mathrm{T} 0$ values (Tympanic temperature immediately after arrival in the recovery room), with $p \square 0.001$. However, there was no significant difference in the temperatures measured at 50 and 60 minutes as shown in (Figure 3 ). 


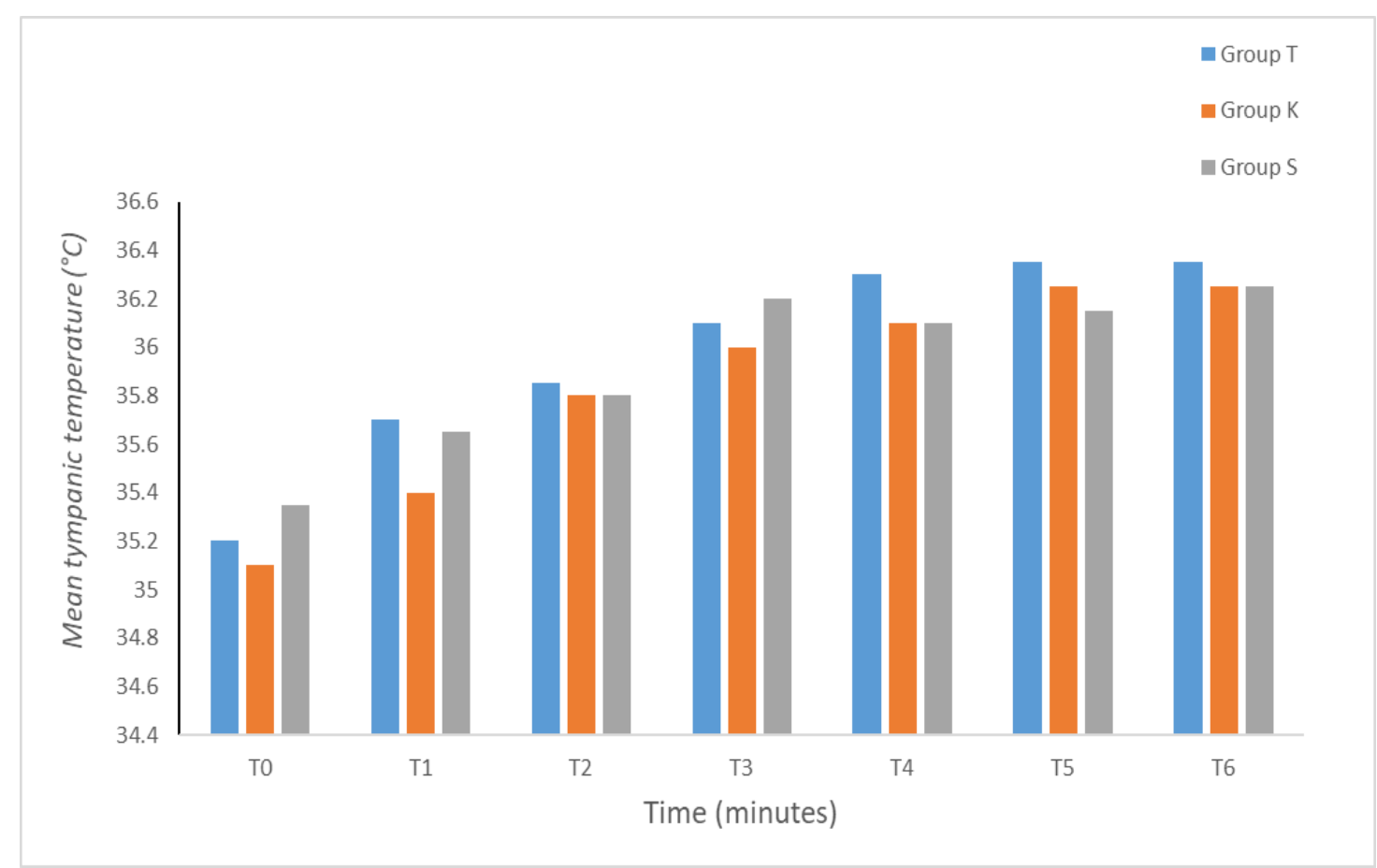

Figure (3) Changes in tympanic temperature with time in the postoperative period among the groups

Regarding perioperative complications such as hypotension, bradycardia, postoperative nausea and vomiting, and hallucination there were no significant differences among the study groups.

Hypotension was seen in eleven (22\%) cases in the tramadol group, nine (18\%) cases in the ketamine group and nine $(18 \%)$ cases in the saline group. All hypotensive episodes were treated with IV crystalloid infusions and $5 \mathrm{mg}$ of IV ephedrine. No patient in any group developed bradycardia.

The sedation score was below 3 in all of the patients. Grade 2 sedation was seen in five cases (10\%) in the tramadol group and seventeen cases (34\%) in the ketamine group. Hallucinations were not noted in any of the study groups (Table 6).

Nausea and vomiting were seen in seventeen (34\%) patients in the tramadol group, eleven (22\%) patients in the ketamine group and fourteen cases $(28 \%)$ in the saline group, and there was no significant difference among the groups regarding the severity of nausea and vomiting ( $p \sqcap 0.100)$, as found in (Table 6).

\begin{tabular}{|l|c|c|c|c|}
\hline & $(\mathbf{n = 5 0})$ Group T & $(\mathbf{n = 5 0 )}$ Group K & $(\mathbf{n = 5 0 )}$ Group S & P-Value \\
\hline Hypotension & $11(22 \%)$ & $9(18 \%)$ & $9(18 \%)$ & 0.842 \\
\hline Nausea \& vomiting & $17(34 \%)$ & $11(22 \%)$ & $14(28 \%)$ & 0.100 \\
\hline $\begin{array}{l}\text { Sedation (Rmsay } \\
\text { score } \leq 2)\end{array}$ & $5(10 \%)$ & $17(34 \%)$ & 0 & $<0.001^{*}$ \\
\hline Bradycardia & 0 & 0 & 0 & \\
\hline Hallucination & 0 & 0 & 0 & \\
\hline
\end{tabular}

Table (6): Incidence of perioperative complications.

Notes: group $\mathrm{K}=$ ketamine, group $\mathrm{T}=$ tramadol and group $\mathrm{S}=$ saline. $*$ is considered significant.

\section{DISCUSSION}

Numerous ideas have been proposed to describe the shivering throughout and after subarachnoid anesthesia. The prime cause of shivering is subarachnoid anesthesia-induced repression of the thermoregulatory mechanism commencing to intraoperative and postoperative hypothermia. So, perioperative shivering happens as a thermoregulatory reply to hypothermia. However, shivering may transpire also with normothermia in the postoperative scene, which recommends that mechanisms other than the decrease of body temperature due to heat loss may also cause shivering. These mechanisms may be adrenal abolition, postoperative agony, sympathetic exaggerated activity, unrepressed spinal reflexes, and the resulted respiratory alkalosis. In the postoperative stage, the patient's recovery may hurt because of shivering. One of the bad results of shivering is the aggravation of postoperative agony due to stretching the surgical incision. ${ }^{10}$

Ketamine is listed as a dissociative anesthetic acts as a non-competitive antagonist of (NMDA) N-methyl-Daspartate receptors which has a role in thermoregulation in sub-anesthetic dosages. Ketamine has an anti-shivering mechanism in shivering restriction either by the $\beta$-adrenergic effect of norepinephrine or by its effect on the hypothalamus. NMDA receptors act in thermoregulation by 
modulation of the noradrenergic and serotoninergic neurons in the locus coeruleus which might share in heat control. ${ }^{11}$

Synthetic opioids can play a role in heat regulation at various mechanisms like Tramadol. One of these mechanisms is serotonin and noradrenaline reuptake repression in the spinal cord which helps serotonin liberation. Also, it has an anti-shivering effect through its action on $\alpha 2$-adrenoceptors, opioids, and kappa receptors. ${ }^{12}$ Tramadol in doses of $0.5-2 \mathrm{mg} / \mathrm{kg}$ is sufficient in managing perioperative shivering with comparable efficacy as that of Pethidine $0.5 \mathrm{mg} / \mathrm{kg}$ with negligible adverse effects. ${ }^{12}$

This prospective, randomized, double-blind, placebo-controlled study reported that $0.2 \mathrm{mg} / \mathrm{kg}$ of ketamine intravenously was more efficient than intravenous $0.5 \mathrm{mg} / \mathrm{kg}$ tramadol in lessening the frequency and magnitude of shivering during subarachnoid anesthesia, compared to the control group.

In the current study, the prevalence of shivering in the control group was $70 \%$. This incidence was high compared with previous studies, ${ }^{13}$ where the incidences were $53.3 \%$. This contrariety could be due to the application of higher ambient temperature $\left(25^{\circ} \mathrm{C}\right)$, extra warming means such as warming of the intravenous fluids and forced warming air that kept the body temperature of the patients in their research. Moreover, current study incidence was high as compared with a study conducted by Wason et al, ${ }^{14}$ where the rate of shivering in the control group was $54 \%$ only. This discrepancy could be assigned to the average sensory block level used: T7 (in their study) vs T6 (in the current study). Moreover, in the current study, the room temperature $\left(22^{\circ} \mathrm{C}-27^{\circ} \mathrm{C}\right)$ was not fixed and all intravenous fluids were not pre-warmed to $37^{\circ} \mathrm{C}$, which could raise the rate of shivering in the control group.

Current study occurrence of shivering was high in comparison with a study done by Hidayah et al, ${ }^{15}$ in that study, the frequency of postoperative shivering in tramadol-group patients in a dose of $(0.5 \mathrm{mg} / \mathrm{kg} \mathrm{IV})$ after subarachnoid anesthesia were $16 \%$ vs $24 \%$ in the control group. This low frequency in the former study could be due to the use of subarachnoid injection of fentanyl in a dose of $25 \mathrm{mcg}$, which has an antishivering impact. Also, in the former study, the percentages of grade 3 and 4 shiverings in the ketamine and saline groups were $19.5 \%$ and $43.9 \%$, respectively. The occurrence of shivering was low in the ketamine group in the current study in correlation with a previous study where the prevalence was recorded as $33 \%$ in the ketamine group. ${ }^{16}$ This contrariety could be credited to the kind of anesthesia used for cesarean section, as general anesthesia was used in their study while subarachnoid anesthesia was used in the current study. Although, the current study occurrence of shivering was low in correlation with a former study ${ }^{17}$ where $10 \%$ of patients in the ketamine group developed grade 3 and 4 shivering. The low incidence of shivering in that study could be attributed to regulated room temperature at 24 ${ }^{0} \mathrm{C}$ to $25{ }^{\circ} \mathrm{C}$ and pre-warming of all intravenous fluids to $37{ }^{\circ} \mathrm{C}$ compared with the current study.

In the current study, the mean tympanic temperature declined following subarachnoid anesthesia in all groups, correlated to baseline readings. The decline in tympanic temperature was not significantly varied among the groups. The decrease in temperature was clinically significant in regard to baseline readings, and hypothermia during subarachnoid anesthesia can be attributed to heat redistribution from the core to the periphery, vasodilation with heat loss and repression of thermoregulation. This was in accordance with a previous study ${ }^{13}$ in which Dexmedetomidine, Tramadol, Granisetron, and control groups were matched and there were no variations among the groups with respect to tympanic temperature decline after subarachnoid anesthesia. This could be due to the same ways of actions of these medicines in the inhibition of shivering through the central thermoregulatory center. Nonetheless, another study ${ }^{17}$ revealed a higher fall in core temperatures in the control group, related with tramadol, clonidine and ketamine groups.

Moreover, in the current study, the tympanic temperature increased postoperatively in the recovery room by time in correlation to temperature readings reported at admittance in the recovery room directly following the surgery, which could be clinically related, although statistically significant differences were not seen. The increase in tympanic temperature might be attributed to the use of a sheet to cover the patient in the recovery room and the restoration of motor and sensory functions over time as the influence of subarachnoid anesthesia subsided.

Furthermore, the rates of perioperative dilemmas such as hallucination, nausea, vomiting, and hypotension were not significantly varied amongst the groups in the current study except for sedation which was significant in ketamine group, as 17 patients (34\%) compared with tramadol group, as 5 patients $(10 \%)$ with p-value $<0.001$. However, Gangopadhyay et al., ${ }^{18}$ remarked large numbers of patients complaining of nausea and vomiting in the tramadol group $(1 \mathrm{mg} / \mathrm{kg})$. This could be due to a high dose of tramadol used in the former study compared with the present study ( $1 \mathrm{vs} 0.5 \mathrm{mg} / \mathrm{kg}$ ).

Besides, the sedation scores were lower than in grade 3 in all patients in the current study. However, seventeen cases in the ketamine group developed grade 2 sedation, though highly significant compared to the tramadol group. This is consonant with a previous study ${ }^{17}$ where ketamine caused a significant grade 3 and 4 sedation compared with saline, clonidine and tramadol groups. Although, high sedation scores in other study ${ }^{17}$ could be because a high dose of ketamine was used in the previous study compared with the current study ( 0.5 vs $0.2 \mathrm{mg} / \mathrm{kg}$ ). 


\section{CONCLUSION}

The prophylactic administration of low-dose ketamine $(0.2 \mathrm{mg} / \mathrm{kg})$ or tramadol $(0.5 \mathrm{mg} / \mathrm{kg})$ intravenously is efficient in lessening the frequency and magnitude of shivering in patients having lower abdominal surgery under subarachnoid anesthesia. The study recommends low-dose IV ketamine or tramadol prophylaxis for patients undergoing lower abdominal surgery under subarachnoid anesthesia with high priority to tramadol. Moreover, additional shivering preventive methods should be practiced.

Limitations of our study: Pethidine, as a gold standard for the prevention of spinal anesthesia shivering, can be used as a control group for other future studies.

\section{REFERENCES}

1. Crowley LJ and Buggy DJ. Shivering and neuraxial anesthesia. Reg Anesth Pain Med. 2008;33(3):241252.

2. Yimer HT, Hailekiros AG, and Tadesse YD. The magnitude and associated factors of postanaesthesia shivering among patients who operated under general and regional anesthesia, Northwest Ethiopia: a cross-sectional study. J Anesth Clin Res. 2015;2015.

3. Talakoub R and Meshkat SN. Tramadol versus meperidine in the treatment of shivering during spinal anesthesia in cesarean section. J Res Med Sci. 2006;11(3):151-155.

4. De Witte J and Sessler DI. Perioperative shivering: physiology and pharmacology. J ASA. 2002;96(2):467-484.

5. Dhiman AA, Patel MG, and Swadia V. Tramadol for control of shivering (comparison with pethidine). Indian J Anaesth. 2007;51(1):28-31.

6. Han JW, Kang HS, Choi SK, Park SJ, Park HJ, and Lim TH. Comparison of the effects of intrathecal fentanyl and meperidine on shivering after cesarean delivery under spinal anesthesia. Korean $J$ Anesthesiol. 2007;52(6):657-662.

7. Al Maruf A, Islam MS, and Hoq N. Effect of tramadol and pethidine on shivering during cesarean section under spinal anesthesia. J Armed Forces Med Coll Bangladesh. 2015;10(2):27-32.

8. Honarmand A and Safavi M. Comparison of prophylactic use of midazolam, ketamine, and ketamine plus midazolam for prevention of shivering during regional anesthesia: a randomized double-blind placebo-controlled trial. Br J Anaesth. 2008;101(4):557-562.
9. Tsai YC and Chu KS. A comparison of tramadol, amitriptyline, and meperidine for post epidural anesthetic shivering in parturients. Anesth Analg. 2001;93(5):1288-1292.

10. Shukla U, Malhotra K, and Prabhakar T. A comparative study of the effect of clonidine and tramadol on post-spinal anesthesia shivering. Indian J Anaesth 2011;55:242-6.

11. Kose EA, Dal D, Akinci SB, Saricaoglu F, and Aypar U. The efficacy of ketamine for the treatment of postoperative shivering. Anesth Analg. 2008;106(1):120-2.

12. Drissen B, and Reimann W. Interaction of the central analgesic, tramadol, with the uptake and release of 5-hydroxytryptamine in the rat brain in vitro. Br J Pharmacol. 1992;105(1):147-51.

13. Ejiro B, Edomwonyi $\mathrm{N}$, and Imarengiaye $\mathrm{C}$. Ondansetron versus tramadol in the prevention of postanaesthesia shivering following cesarean section under spinal anesthesia. African J Anaesth Intensive Care. 2014;14(1):6-11.

14. Wason R, Jain N, Gupta P, and Gogia AR. Randomized double-blind comparison of prophylactic ketamine, clonidine, and tramadol for the control of shivering under neuraxial anesthesia. Indian J Anaesth. 2012;56(4):370-375.

15. Hidayah MN, Liu CY, and Joanna OS. Ketamine and tramadol for the prevention of shivering during spinal anesthesia. Clin Ter. 2014; 165(4):193-198.

16. Eydi M, Golzari SE, Aghamohammadi D, Kolahdouzan K, Safari S, and Ostadi Z. Postoperative management of shivering: a comparison of pethidine vs. ketamine. Anesth Pain Med. 2014;4(2):e15499.

17. Shakya S, Chaturvedi A, and Sah BP. Prophylactic low dose ketamine and ondansetron for prevention of shivering during spinal anesthesia. $J$ Anaesthesiol Clin Pharmacol. 2010;26(4):465469.

18. Gangopadhyay S, Gupta K, Acharjee S, Nayak SK, Dawn S, and Pillai G. Ketamine, tramadol and pethidine in the prophylaxis of shivering during spinal anesthesia. $J$ Anaesthesiol Clin Pharmacol. 2010;26(1):59-63. 